\title{
Prediction of Spread and Regional Development of Hop Powdery Mildew: A Network Analysis
}

\author{
David H. Gent, ${ }^{1, \dagger}$ Sharmodeep Bhattacharyya, ${ }^{2}$ and Trevor Ruiz ${ }^{2}$ \\ ${ }^{1}$ Forage Seed and Cereal Research Unit, U.S. Department of Agriculture Agricultural Research Service, Corvallis, OR 97331 \\ 2 Department of Statistics, Oregon State University, Corvallis, OR 97331 \\ Accepted for publication 28 February 2019.
}

\begin{abstract}
Dispersal is a fundamental aspect of epidemic development at multiple spatial scales, including those that extend beyond the borders of individual fields and to the landscape level. In this research, we used the powdery mildew of the hop pathosystem (caused by Podosphaera macularis) to formulate a model of pathogen dispersal during spring (May to June) and early summer (June to July) at the intermediate scale between synoptic weather systems and microclimate (mesoscale) based on a census of commercial hop yards during 2014 to 2017 in a production region in western Oregon. This pathosystem is characterized by a low level of overwintering of the pathogen as a result of absence of the ascigerious stage of the fungus and consequent annual cycles of localized survival via bud perennation and pathogen spread by windborne dispersal. An individual hop yard was considered a node in the model, whose disease status in a given month was expressed as a nonlinear function of disease incidence in the preceding month, susceptibility to two races of the fungus, and disease spread from other nodes as influenced by their disease incidence, area, distance away,

and wind run and direction in the preceding month. Parameters were estimated by maximum likelihood over all 4 years but were allowed to vary for time transition periods from May to June and from June to July. The model accounted for 34 to $90 \%$ of the observed variation in disease incidence at the field level, depending on the year and season. Network graphs and analyses suggest that dispersal was dominated by relatively localized dispersal events $(<2 \mathrm{~km})$ among the network of fields, being mostly restricted to the same or adjacent farms. When formed, predicted disease attributable to dispersal from other hop yards (edges) associated with longer distance dispersal was more frequent in the June to July time transition. Edges with a high probability of disease transmission were formed in instances where yards were in close proximity or where disease incidence was relatively high in large hop yards, as moderated by wind run. The modeling approach provides a flexible and generalizable framework for understanding and predicting pathogen dispersal at the regional level as well as the implications of network connectivity on epidemic development.
\end{abstract}

Pathogen dispersal is essential to epidemic development, yet fundamental knowledge of dispersal is limited for most diseases, especially over broad spatial extents (Meentemeyer et al. 2012). Long-distance dispersal of pathogens is a complex and dynamic process that depends on characteristics of the organism, conditions in the initial disease focus, and covariates associated with host population, weather, and landscape connectivity of the host and the pathogen (Meentemeyer et al. 2012; Ostfeld et al. 2005; Severns et al. 2018). Landscape connectivity refers to the functional linkage among fields based on both the physical juxtaposition and dispersal capabilities of an organism (With et al. 1997). Connectivity is an important factor in determining the spatial and temporal dynamics of epidemics, and landscape heterogeneity can greatly affect the velocity, direction, and severity of epidemics (Margosian et al. 2009; Mundt and Sackett 2012; Ostfeld et al. 2005).

†Corresponding author: D. H. Gent; dave.gent@usda.gov

Funding: Financial support was provided by the U.S. Department of Agriculture (USDA) Agricultural Research Service (CRIS 2072-21000-051-00D), the Hop Research Council, the USDA National Institute of Food and Agriculture (Specialty Crops Research Initiative Project 2014-07882), the Washington State Department of Agriculture (Specialty Crops Research Block Grant K1508), and the Oregon Hop Commission. Mention of a trademark, proprietary product, or vendor does not constitute a guarantee or warranty of the product by the USDA and does not imply its approval to the exclusion of the products or vendors that may also be suitable.

*The $\boldsymbol{e}$-Xtra logo stands for "electronic extra" and indicates that seven supplementary figures and one supplementary file are published online.

The author(s) declare no conflict of interest.

This article is in the public domain and not copyrightable. It may be freely reprinted with customary crediting of the source. The American Phytopathological Society, 2019.
Models expressing the risk of disease spread can be nonspatial, spatially explicit, or spatially implicit (Meentemeyer et al. 2012; Ostfeld et al. 2005). Spatially implicit models may include those describing metapopulations and descriptive models of disease development as a result of dispersal (Mundt et al. 2009a, b); however, these models do not directly consider the spatial dependence of neighboring sites, whereas spatially explicit models do. Probabilistic analysis of long-distance dispersal with all possible covariate factors in process-based submodels is difficult (Meentemeyer et al. 2012) and there can be much uncertainty in input variables and subsequent predictions (Aylor 2017). Lagrangian stochastic simulation models have been used as a framework for understanding and predicting transport of pathogen propagules (Aylor 2017). As noted by Firester et al. (2018), this approach requires extensive computation time and complex requirements for data inputs. Predicting dispersal at the mesoscale level, the scale of weather systems between the synoptic scale and microclimates ranging from a few to tens of kilometers, is further complicated because microclimate, canopy architecture, terrain and other landscape features, and stochastic effects influence aspects of dispersal, transport, and deposition of inoculum. Few models attempt to model biophysical dispersal processes at multiple scales resulting from multiple sources of inoculum, the latter typically not being known, and most models of long-distance dispersal estimate only relative hazard from inoculum originating from within-field or distant sources (Aylor 2017).

Inference is the primary goal in fitting statistical models of dispersal patterns based on the primary determinants of dispersal such as pathogen source strength, location of host populations, and other relevant covariate information (Firester et al. 2018; Meentemeyer et al. 2012; Sutrave et al. 2012). Such a model can be formulated as a network spreading model (Firester et al. 2018; Garrett et al. 2018; Sanatkar et al. 2015; Sutrave et al. 2012). The 
study of properties of networks is an active area of research across many disciplines, including epidemiology (Shaw and Pautasso 2014). Networks are sets of elements (nodes) connected by links (edges), with the links representing physical or social connection or transmission of energy, matter, or information (Jeger et al. 2007; Pautasso and Jeger 2014). Conceptualizing epidemics as abstract networks is useful for describing interactions between individual fields, metapopulations, or entire regions and makes explicit when and where to focus efforts to reduce disease spread most efficiently (Chadès et al. 2011; Eubank et al. 2004; Shaw and Pautasso 2014).

Statistical modeling of epidemiological processes is quite classical (Goffman and Newill 1964; Kermack and McKendrick 1991), and there is an extensive body of work in statistical epidemiology (Anderson and May 1992; Keeling and Rohani 2011). Ongoing research in this area includes network-based inference on epidemiological spread of diseases (Grassberger 1983; Liu et al. 2003; Pastor-Satorras and Vespignani 2001). However, most of these works focus on physical or other contact processes (Bajardi et al. 2011; Isella et al. 2011; Valdano et al. 2018) and not long-distance dispersal by airborne inoculum, although some notable examples exist (Meyer et al. 2017; Pleydell et al. 2018).

In plant pathology contexts, network models most often have been applied to problems of disease spread on a regular lattice of susceptible and infected individuals (Jeger et al. 2007). Network models have found applications in understanding routes of pathogen dissemination in commerce (Hernandez Nopsa et al. 2015; Jeger et al. 2007), dissemination of physical materials such as seeds and plant genetic resources (Buddenhagen et al. 2017; Garrett et al. 2017), and communication pathways (Del Ponte et al. 2017). Network concepts and models have less often been applied to aerially transmitted pathogens, although some examples exist (Sanatkar et al. 2015; Sutrave et al. 2012). For aerially dispersed diseases, an abstract (inferred) network can be formulated in which nodes are locations or individuals and the transmission of disease between two nodes is described by an edge, where the edge weight is proportional to the probability of transmission.

Two examples of such models were presented for soybean rust at the continental scale as described by Sutrave et al. (2012) and modified by Sanatkar et al. (2015). These authors formulated susceptible-infected (SI) models to describe the within-season spread of soybean rust between counties in the United States based on local information of host availability and wind speed and direction. The network representation of this model had timevarying edge weights representing the probability that soybean rust develops in a county ("sink" node $i$ ) as a result of pathogen dispersal from another county ("source" node $j$ ). Edge weights for time $t$, $u_{i j}(t)$, were expressed as follows:

$$
u_{i j}(t)=a_{1} w(t)\left(d_{i} d_{j}\right) \exp ^{\left(a_{2} l_{i j}\right)}
$$

or in a variant form

$$
u_{i j}(t)=a_{1} w(t)\left(d_{i}+d_{j}\right) \exp ^{\left(a_{2} l_{i j}\right)}
$$

where $w(t)$ is a scalar projection of maximum wind speed at source node $j$ in the direction of sink node $i ; d_{i}$ and $d_{j}$ are host densities in nodes $i$ and $j$, respectively; $l_{i j}$ is the Euclidian distance between nodes $i$ and $j$; and $a_{1}$ and $a_{2}$ are parameters. Infection data for each of the $N$ nodes were considered as observations of $N$ independent discrete-time finite Markov chains on an SI state space. The conditional probability of node $i$ becoming diseased at $t$ given $t-1, p_{i, t}$, was stipulated as an expression of a mean field approximation updated at each time step with appropriate values for the wind variables; parameter values for $a_{1}$ and $a_{2}$ were selected from a grid search of values that minimized chosen error metrics of observed and expected disease status (Sutrave et al. 2012). Similar network model structures with different edge weights and parameter selection methods were also utilized. These approaches blend processbased aspects of dispersal with empirical components.

General frameworks for modeling dispersal and forming edge weights have not been applied at the spatial extents considered here. To do this, a system is needed in which epidemics originate from localized sources of inoculum and spread at the mesoscale level. One such system is powdery mildew of hop caused by Podosphaera macularis, an obligately biotrophic fungus that produces annual cycles of pathogen dispersal within and among farms, eventually producing regional epidemics (Gent et al. 2019). The fungus persists from season to season in the U.S. Pacific Northwest by means of infection of crown buds because the ascigerous stage of the pathogen is absent in this region (Gent et al. 2008; Wolfenbarger et al. 2015). Bud infection and successful overwintering of the fungus leads to the emergence of heavily infected shoots in early spring, termed "flag shoots" (Jarvis et al. 2012; Liyanage and Royle 1976; Mahaffee et al. 2009). Flag shoots typically occur at a low frequency in commercial hop yards in Oregon and are found on only $0.05 \%$ of plants (Gent et al. 2019). Thus, the disease is highly focal in the early stages of epidemics but spreads to an increasing number of plants and yards as the season progresses as a result of dispersal both within and among fields. At the end of the cropping season, the pathogen becomes locally extinct in most fields as a result of the low frequency of overwintering survival (Gent et al. 2018, 2019), generating annual cycles of extinction and colonization that are amenable to modeling dispersal at the spatial scale of interest.

We derived a statistical approach to modeling disease spread among nodes at the mesoscale and applied our approach in producing a network analysis of the extinction-colonization cycle of hop powdery mildew among commercial yards in a growing region in western Oregon. This research was motivated by multiple objectives. First, we sought to describe dispersal in terms of covariates relevant for disease development and spread at the landscape level. Second, we sought to understand the implications of this model on the dynamics of disease spread and the structure of connections within the network of hop yards. Finally, we sought to identify highly connected nodes where intervention and disease reduction may change disease progression substantially.

\section{MATERIALS AND METHODS}

Description of disease assessments and data sets. Measurements of powdery mildew and associated risk factors were obtained from sampling conducted in commercial hop yards in Oregon during each year from 2014 to 2017, described in part in Gent et al. (2019). The data set was a census of all hop yards on a group of farms in western Oregon, irrespective of cultivar susceptibility to powdery mildew, intended to capture initial occurrence of the disease (attributable to bud perennation) and subsequent spread. Other hosts of $P$. macularis are not known, although feral plants and plants produced in residential gardens may by a source of inoculum but were not sampled. Similarly, hop plants produced in greenhouses were not sampled. The contribution of these potential, yet unknown, sources of the host is accounted for implicitly in the model described below through their contribution to baseline disease risk.

The cultivars evaluated are detailed in Gent et al. (2019). Susceptibility to powdery mildew varies among these cultivars from completely resistant (e.g., Crystal) to highly susceptible (e.g., Apollo) (Gent et al. 2015; Wolfenbarger et al. 2016, 2017). Eight to 10 farms were sampled, year dependent, spanning from near the cities of Silverton to Hubbard, Oregon (maximum distance between yards, $26 \mathrm{~km}$ ). In total, 107 yards were assessed in 2014, 123 in 2015, 125 in 2016, and 134 in 2017.

Disease assessments were conducted monthly in each of April, May, June, and July; assessments conducted in April were not directly relevant for the analyses described below because of the 
sparsity of disease development from April to May (Table 1; Supplementary Fig. S1). The incidence of plants with powdery mildew was assessed using a modification of the methods described by Turechek et al. (2001) and Turechek and Mahaffee (2004). Each yard was divided into strata of 20 rows, and at least two strata per yard were sampled by evaluating 50 to 200 hills (referred to hereafter as plants) in one transect (row) per strata. The assessments in April and May were intended to detect flag shoots and secondary spread early in the epidemic, whereas disease assessments in June and July were focused on secondary spread to leaves. Plants were relatively small during assessments in April and May, with shoots being no more than $1 \mathrm{~m}$ tall. During June and July, plants ranged in height from approximately 2 to $6 \mathrm{~m}$ depending on cultivar, year, and farm.

Race characterization. The race of the pathogen present in a given hop yard determines which other yards could be a possible source or sink of the pathogen. Three races of $P$. macularis that display differential host genotype adaptation in the Pacific Northwest have been described (Gent et al. 2017; Wolfenbarger et al. 2016). These races consist of isolates virulent to cultivars possessing the R-genes $\mathrm{Rb}, \mathrm{R} 3$, and R5 (race Vb,V3,V5); isolates virulent on Rb, R3, R4, R5, and R6 (race Vb,V3,V4,V5,V6) (Wolfenbarger et al. 2016); and isolates that possess virulence to $\mathrm{Rb}, \mathrm{R} 3$, and R5 and additionally are virulent on the cultivar Cascade (dubbed Cascade-adapted) (Gent et al. 2017). Race Vb,V3,V5 can cause powdery mildew on many cultivars (Gent et al. 2015) but cannot cause powdery mildew on cultivars possessing the resistance gene R6, which is present in numerous cultivars grown in the region (e.g., Nugget) (Wolfenbarger et al. 2016). However, race $\mathrm{Vb}, \mathrm{V} 3, \mathrm{~V} 4, \mathrm{~V} 5, \mathrm{~V} 6$ can cause disease on both cultivars possessing R6 and those lacking R6. Although R6-virulent isolates can infect plants that do not possess R6, there are quantitative differences in fitness between isolates with or without R6 virulence (Wolfenbarger et al. 2016). In certain genetic backgrounds with and without R6, isolates with R6 virulence have a slightly longer latent period, may cause fewer colonies per unit area, and produce fewer conidia. Race Vb,V3,V5 was the most commonly encountered virulence found in P. macularis in Oregon prior to 2014, but this race has been gradually displaced by race $\mathrm{Vb}, \mathrm{V} 3, \mathrm{~V} 4, \mathrm{~V} 5, \mathrm{~V} 6$ (Wolfenbarger et al. 2016). The cultivar Cascade possesses partial resistance to powdery mildew and can become diseased at low levels by nearly all extant isolates of $P$. macularis present in the Pacific Northwest (Gent et al. 2017). Cascade-adapted isolates display a cultivar-specific adaptation to Cascade, are most common in Washington State, and were confirmed only in one hop yard in Oregon during the study period of 2014 to 2017. Therefore, this race was considered inconsequential for the present study and ignored.

In instances where a cultivar is known to possess R6, the pathogen race present when powdery mildew is observed must necessarily possess R6 virulence (i.e., race Vb,V3,V4,V5,V6). Such inoculum could have originated from any other susceptible cultivar, including those lacking R6, and conversely inoculum possessing R6 virulence could infect any other susceptible cultivar. In contrast, when powdery mildew is present on cultivars lacking R6, the number of yards at risk of disease depends on the race of the pathogen present.

Efforts were thus made to determine whether the race present in yards planted to cultivars lacking R6 resistance possessed R6

TABLE 1. Proportion of hop yards and plants with powdery mildew during April to July of 2014 to 2017 in a production area in western Oregon

\begin{tabular}{|c|c|c|c|c|c|c|c|c|}
\hline \multirow[b]{2}{*}{ Month } & \multicolumn{2}{|c|}{2014} & \multicolumn{2}{|c|}{2015} & \multicolumn{2}{|c|}{2016} & \multicolumn{2}{|c|}{2017} \\
\hline & Yards & Plants & Yards & Plants & Yards & Plants & Yards & Plants \\
\hline April & 0.05 & 0.001 & 0.02 & 0.0001 & 0.02 & 0.0002 & 0.03 & 0.00009 \\
\hline May & 0.10 & 0.01 & 0.03 & 0.0004 & 0.04 & 0.002 & 0.05 & 0.0002 \\
\hline June & 0.51 & 0.12 & 0.29 & 0.06 & 0.35 & 0.08 & 0.17 & 0.02 \\
\hline July & 0.65 & 0.11 & 0.27 & 0.07 & 0.28 & 0.06 & 0.33 & 0.04 \\
\hline
\end{tabular}

virulence. Methods to determine R6 virulence were as described by Wolfenbarger et al. (2016). In brief, when powdery mildew was first detected in a hop yard, up to five flag shoots or leaves with powdery mildew were collected from these yards, and propagules were transferred individually as a heterogeneous inoculum source (not reduced to a clonal isolate) onto detached leaves of the susceptible cultivar Symphony (as a positive control) and the R6-differential cultivar Nugget. After 2 to 3 weeks of incubation at $18^{\circ} \mathrm{C}$, isolates that produced sporulating colonies on Nugget were deemed R6 virulent (race $\mathrm{Vb}, \mathrm{V} 3, \mathrm{~V} 4, \mathrm{~V} 5, \mathrm{~V} 6$ ), whereas isolates that caused disease on Symphony but not Nugget were deemed non-R6-virulent (race Vb,V3,V5).

Geographical and weather data. Information on the area, perimeter, and centroid of each yard was obtained from ArcGIS (Esri, Redlands, CA). Based on the centroid of each yard, hourly wind speed at $10 \mathrm{~m}$ height and wind direction above the surface friction layer for each field was obtained from Fox Weather (Fortuna, CA) using a historical reconstruction process. The general approach for producing the weather reconstruction was that 32-km-resolution, gridded North American Regional Reanalysis data sets at 3-h time steps were obtained from the National Oceanic and Atmospheric Administration. These data sets were used as inputs to the Weather Research and Forecasting model to produce $12-\mathrm{km}$-resolution data sets, which were further downscaled to $4 \mathrm{~km}$ in a nested run, before interpolating to hourly data at $1.5 \mathrm{~km}$ resolution using the proprietary Fox Weather MtnRT forecasting product.

From the hourly weather data, a wind run variable was calculated in each of 16 cardinal directions for each hop yard for the days between each of the disease assessments (i.e., monthly aggregation). For each yard, wind run was calculated as the product of mean wind speed and the proportion of hours when the wind was emanating in each cardinal direction.

Generalized regression model framework. The modeling approach presented here employed a generalized regression framework relating yard-by-yard disease levels to autoinfection at the yard level and pathogen dispersal. For this, data were aggregated to the yard level as described in detail in Supplementary File S1. The dispersal component was based on pairwise yard attributes (distance, wind run, and source strength) and was similar in form to the link weights used in the SI models of Sanatkar et al. (2015) and Sutrave et al. (2012). As such, the dispersal component facilitated post hoc (i.e., postparameter estimation) graph formation and subsequent network analyses. The key difference between this generalized regression approach and previous studies is that statistical inference using likelihood methods is employed to estimate parameters directly from observed data, which is considerably more powerful and generalizable than simulation-and-error-minimization approaches.

Model specification. Generalized regression models, as a broad class of statistical models, comprise a parametric probability distribution for a response variable conditional on covariate information (a "probability model") and a functional form for the conditional mean of the response in terms of the covariates (a "predictor function"). For the hop powdery mildew data, the response variable considered was the number of diseased plants identified in a given yard in a particular month and year among the sample of plants taken from that yard in that month. This is denoted by $Y_{i}$, the number of diseased plants among a sample of $n_{i}$ plants, with $i=1, \ldots, N$ indexing yard identity. The relevant covariates were disease levels from the previous month and yard size, as well as pairwise distances and wind runs between yards (Table 2).

Wind runs between target yard $i$ and source yard $j$ were calculated as projections from wind runs on the 16 cardinal directions at the source field. The method of projections was as follows: (i) to scale average wind speed by the percentage of time for each cardinal direction; (ii) to select cardinal directions that are at an angle $<\frac{\pi}{2}$ 
from the $i-j$ direction to avoid cancellations between opposing directions; (iii) to orthogonally project each scaled wind vector from the selected directions onto the $i-j$ direction; and (iv) to take as $w_{i j}$ the average of the resulting orthogonal projections. As noted previously, wind speed and direction were reported hourly but aggregated to monthly values.

The probability model chosen to approximate aggregated yard disease observations $Y_{i}$ was binomial; $Y_{i}$ was assumed to be a conditionally independent binomial random variable, given the disease status for all yards in the preceding month.

$$
Y_{i} \mid x_{i} \sim b\left(n_{i}, p_{i}\right) \quad i=1, \ldots, N
$$

where $n_{i}$ is the number of plants sampled from yard $i$ and $p_{i}$ is the probability that a plant from field $i$ is diseased. The predictor function was expressed on the log-odds scale using the logit transformation, $\operatorname{logit}(x)=\log \left(\frac{x}{1-x}\right)$, and involved an intercept expressing baseline disease probability, an autoinfection component for within-yard spread, and a dispersal component for between-yard spread:

$$
\log \left(\frac{p_{i}}{1-p_{i}}\right)=\beta+\delta\left(\frac{\tilde{y}_{i}}{n_{\tilde{y}_{i}}}\right)+\gamma \sum_{j=1}^{M_{i}}\left(\frac{a_{j} z_{j}}{n_{z_{j}}} w_{i j} \exp \left\{-\alpha d_{i j}\right\}\right)
$$

Covariates are given in Table 2 and parameter interpretations are given in Table 3 . Equations 1 and 2 fully specify the model of expected disease status in a given month as a function of disease levels in the preceding month and disease spread from other sources as influenced by their level of disease, area, distance away, and wind run and direction in the preceding month. We note that many other functional forms of equation 2 could be specified to account for other covariates or dispersal relationships, such as power law expressions and other variant forms.

As noted previously, there were two races of the powdery mildew fungus of relevance, an R6-virulent race and a non-R6-virulent race. In the hop powdery mildew data set, the cultivar grown at each yard was categorized for susceptibility to each of the two races (susceptible or not), and infected yards were assessed for virulence race as described above. This information was used to group target yards with potential sources of inoculum, in effect constraining the model so that disease caused by certain races at certain source yards made no contribution to disease risk at target yards with resistance to these races. Yards that were resistant to the non-R6-virulent race (i.e., those that possessed R6 resistance) could only be infected by R6-virulent races, whereas yards that were susceptible to non-R6virulent races could be infected by both races of the pathogen. This constraint was imposed by fitting separate models for the two source-target groups. Where necessary, model parameters for the two source-target groups will be distinguished using subscripts and a simple verbal convention: the source-target group comprising cultivars possessing R6 and sources with R6-virulence and

TABLE 2. Covariate notations for each yard of interest $i=1, \ldots, N$ in a particular month, and all other yards $j=1, \ldots M_{i}$, relative to $i^{\mathrm{a}}$

\begin{tabular}{ll}
\hline Variable & \multicolumn{1}{c}{ Description } \\
\hline$\tilde{y}_{i}$ & Number of diseased plants at yard $i$ in the prior month \\
$n_{\tilde{y}_{i}}$ & Number of plants sampled at yard $i$ in the prior month \\
$a_{i}$ & Area (acres) of yard $i$ \\
$z_{j}$ & Number of diseased plants at yard $j$ in the prior month \\
$n_{z_{j}}$ & Number of plants sampled at yard $j$ in the prior month \\
$a_{j}$ & Area (acres) of yard $j$ \\
$d_{i j}$ & Distance (in kilometers) from centroids of yard $i$ to yard $j$ \\
$w_{i j}$ & Wind vector on $i-j$ direction in the prior month \\
\hline
\end{tabular}

a The single-subscript variables are nodewise covariates and the dual-subscript variables are network covariates. When succinct notation is required, the entire collection of these covariates for yard $i$ is denoted by $x_{i}$. properties thereof will be referred to using "R6 cultivars" in descriptions and the subscript 1 with notation (e.g., "R6 cultivar network", $\left.\beta_{1}\right)$, and the source-target group comprising cultivars not possessing R6 and all virulence types and its properties will be referred to using "non-R6 cultivars" and the subscript 2.

Parameter estimation. One functional form of the predictor was constructed (equation 2), and parameters were estimated separately for each of the two transitions from May to June and from June to July using data from all 4 years. Therefore, the estimated parameters vary in each time transition but not annually. This results in two fitted models of disease development and spread, one for the May to June transition and one for the June to July transition.

Parameters were estimated by maximum likelihood and computed numerically via quasi-Newton methods. For data from a month of interest in a particular year $l$, the joint log-likelihood for the data according to equations 1 and 2 is a sum over the $N_{l}$ yards:

$$
1_{l}(\beta, \delta, \gamma, \alpha)=\sum_{i=1}^{N_{l}}(f \circ g \circ h)\left(\beta, \delta, \gamma, \alpha ; y_{i}, x_{i}\right)
$$

where $f$ denotes the binomial log-likelihood density as a function of $\frac{p}{1-p}, g$ denotes the inverse logit function, $h$ represents the functional form of the predictor, and the parameter subscripts are suppressed so $\beta=\left(\beta_{1}, \beta_{2}\right)$ and so on. Maximum likelihood estimates were computed for the May to June transition and June to July transition after aggregating data across the years 2014 to 2017, by summing $l_{l}$ in equation 3 over the year index $l$ :

$$
1(\beta, \delta, \gamma, \alpha)=\sum_{l=1}^{4} \sum_{i=1}^{N_{l}} 1_{l}\left(\beta, \delta, \gamma, \alpha ; y_{i}, x_{i}\right)
$$

Parameters were estimated by solving the optimization problem:

$$
(\hat{\beta}, \hat{\delta}, \hat{\gamma}, \hat{\alpha})=\arg \min _{(\beta, \delta, \gamma, \alpha)}\{-1(\beta, \delta, \gamma, \alpha)\}
$$

A quasi-Newton optimization method was used with Hessian approximations at each iteration, and asymptotic confidence intervals were calculated using the Hessian approximation in the quasi-Newton algorithm at the stopping value.

Prediction of disease levels. Given parameter estimates $\hat{\beta}, \hat{\delta}, \hat{\gamma}$, and $\hat{\alpha}$ for one of the two time transitions, for any of the observed yards the expected disease $\mathrm{E}\left(Y_{i} \mid x_{i}\right)=n_{i} \hat{p}_{i}$ was calculated as follows:

$$
\widehat{p_{i}}=\operatorname{logit}^{-1}\left(\beta+\delta\left(\frac{\tilde{y}_{i}}{n_{\tilde{y}_{i}}}\right)+\gamma \sum_{j=1}^{M_{i}}\left(\frac{a_{j} z_{j}}{n_{z_{j}}} w_{i j} \exp \left\{-\alpha d_{i j}\right\}\right)\right)
$$

Furthermore, for the response variable $Y_{i}^{*}$ associated with an $i$ th hypothetical (and healthy) yard at an arbitrary spatial location, the covariates $z_{j}, n_{z j}$, and $a_{j}$ for observed sources at the prior month, and $d_{i j}$ and $w_{i j}$ for distance and wind run between the hypothetical yard and observed sources are all well defined. With these quantities we estimated disease probability attributable to spread as follows:

TABLE 3. Interpretation of parameters in equation 2

\begin{tabular}{ll}
\hline Parameter & \multicolumn{1}{c}{ Interpretation } \\
\hline$\beta$ & $\begin{array}{c}\text { Baseline log-odds of disease, after accounting for } \\
\text { autoinfection and disease spread } \\
\text { Change in log-odds of disease associated with autoinfection at } \\
\text { the yard scale, after accounting for disease spread }\end{array}$ \\
$\gamma$ & $\begin{array}{c}\text { Distance-adjusted change in log-odds of disease associated } \\
\text { with disease spread from other yards, after accounting for } \\
\text { autoinfection }\end{array}$ \\
$\alpha$ & $\begin{array}{c}\text { Dispersal parameter providing distance adjustment to change } \\
\text { in log-odds of disease associated with individual sources; } \\
\text { scales latter exponentially with distance away from target }\end{array}$ \\
\hline
\end{tabular}




$$
\hat{p}_{i}^{*}=\operatorname{logit}^{-1}\left(\beta+\gamma \sum_{j=1}^{M_{i}}\left(\frac{a_{j} z_{j}}{n_{z_{j}}} w_{i j} \exp \left\{-\alpha d_{i j}\right\}\right)\right)
$$

Thus, not only can expected disease at observed fields be calculated according to the model after parameter estimation, but an estimated disease probability surface can also be constructed by continuous interpolation between pointwise spatial predictions.

Following this method, as newly planted yards were occasionally added in some months or years, this change was easily accommodated by adding the observed response, calculating the necessary covariates in parallel fashion to those used for hypothetical fields in equation 7, and setting the prior disease level at zero (its true value). Similarly, yards removed are accommodated easily by omitting the response but including its contribution as a source in the summation of the dispersal component of the model. This capacity to accommodate changing numbers of nodes across time transitions is one of the strengths of this approach.

Network inference. Graph construction. The dispersal component of equation 2 allows post hoc construction of a disease transmission network. From equation 2, the contribution of the $j$ th yard to the log-odds of disease at yard $i$ is

$$
\gamma \frac{a_{j} z_{j}}{n_{z_{j}}} w_{i j} \exp \left\{-\alpha d_{i j}\right\}
$$

which is zero whenever the $j$ th yard is uninfected and nonzero otherwise (although possibly quite small). The quantity in equation 8 therefore has a natural interpretation as an edge weight for the directed edge from $j$ to $i$ in a network linking the yards as nodes based on risk of disease transmission.

Once parameters were estimated, the edge weights in equation 8 were calculated explicitly for every pair of yards and thresholded on the probability scale (rather than the log-odds scale) by considering probability of disease at yard $i$ associated with yard $k$, which is the quantity

$$
\begin{aligned}
& \Delta p_{k i}=\operatorname{logit}{ }^{-1}\left(\beta+\delta\left(\frac{\tilde{y}_{i}}{n_{\tilde{y}_{i}}}\right)+\gamma \sum_{j=1}^{M_{i}}\left(\frac{a_{j} z_{j}}{n_{z_{j}}} w_{i j} \exp \left\{-\alpha d_{i j}\right\}\right)\right) \\
& -\operatorname{logit}^{-1}\left(\beta+\delta\left(\frac{\tilde{y}_{i}}{n_{\tilde{y}_{i}}}\right)+\gamma \sum_{j=1, j \neq k}^{M_{i}}\left(\frac{a_{j} z_{j}}{n_{z_{j}}} w_{i j} \exp \left\{-\alpha d_{i j}\right\}\right)\right)
\end{aligned}
$$

A threshold $c$ was chosen so that there is an edge from $k$ to $i$ whenever $\Delta p_{k i}>c$. The graph of interest $G=(V, E)$ then has vertex set $V$ comprising each yard and edge set $E$ defined by the rule

$$
(k, i) \in E \Leftrightarrow \Delta p_{k i}>c
$$

for every pair of yards $(k, i) \in V \times V$.

A single value of $c$ was chosen for all years and both networks (R6 cultivars and non-R6 cultivars), but separate thresholds were chosen for the two transition periods. These thresholds were selected by a method based on receiver operating characteristic (ROC) curve analysis that maximized binary classification accuracy. Although the analysis presented here took a quantitative approach and sought to tie threshold selection to classification accuracy, alternative threshold selection methods may be more appropriate in other contexts, such as identification of lowprobability disease transmission events. Graphs were formed for each time transition in every year, and also for each cultivar susceptibility class, totaling 16 graphs (two per time transition per year).

Degree centrality. After network construction, nodewise outward degree centralities were calculated for each graph. For a given graph, the outward degree centrality of the $i$ th node is simply the number of outward-directed edges originating at that node:

$$
d_{k}=\sum_{i} 1\{(k, i) \in E\}
$$

Although numerous other centrality measures might be used (Newman 2010), it was found that in this application the set of highly central yards was consistent across centrality measures; thus, the measure most directly interpretable in the context of this application was chosen. For each graph, the yards were ordered by degree centrality and yard metadata were tabulated for the most central yards and examined qualitatively. Metadata included grower, spring pruning method, virulence race present, and whether there was a flag shoot or otherwise preexisting disease in that yard. Correlates of degree centrality were sought among this information by comparing metadata from the most central nodes in each of the 16 graphs and determining whether any specific characteristics were overrepresented in those highly central yards relative to the overall data set.

\section{RESULTS}

Description of disease assessments and data sets. In all 4 years, powdery mildew was detected at low levels in April (1.6 to $4.6 \%$ of hop yards) as flag shoots. The incidence of yards with disease increased progressively each month until June or July, spreading to affect 28 to $65 \%$ of yards, year dependent. Qualitatively, there appeared to be a spatial association between where powdery mildew was first detected and where the disease later developed and the incidence of disease detected.

Powdery mildew was observed at some level on all cultivars except Amarillo (one yard), Crystal (nine yards), and Saaz (one yard). Among these cultivars, Amarillo and Saaz are known to be susceptible to the disease, whereas Crystal is resistant to all of the predominant races of $P$. macularis present in the western United States (Gent et al. 2015; Wolfenbarger et al. 2017).

Generalized regression model framework. Parameter estimation. Parameter estimates for equation 2 differed by month and cultivar susceptibility groups for most parameters (Table 4). Of particular note, estimates for $\delta$ and $\gamma$, the parameters describing autoinfection and disease spread, were less in the June to July transition compared with the May to June transition; estimates of $\beta$ and $\alpha$, the parameters describing baseline disease risk owing to unexplained factors and dispersal, were reduced relatively less or not at all.

Error quantification. A holdout procedure was used to assess model adequacy: 1 year of data were held out at a time, parameters were estimated from the remaining data, and expected disease levels were calculated for the withheld data. A comparison of observed and expected disease levels for each held-out year is shown in the mean absolute error portion of Table 5; mean absolute

TABLE 4. Parameter estimates and confidence intervals (CIs) for model fit to May to June transition and June to July transition

\begin{tabular}{lcccccc}
\hline & & \multicolumn{2}{c}{ May to June } & & \multicolumn{2}{c}{ June to July } \\
\cline { 3 - 4 } \cline { 6 - 7 } Term $^{\mathrm{a}}$ & Parameter $^{\mathrm{b}}$ & Estimate & $(95 \% \mathrm{CI})$ & & Estimate & $(95 \% \mathrm{CI})$ \\
\hline Intercept & $\beta_{1}$ & -1.85 & $(-1.90,-1.81)$ & & -2.51 & $(-2.61,-2.42)$ \\
& $\beta_{2}$ & -3.86 & $(-3.92,-3.80)$ & & -4.13 & $(-4.22,-4.04)$ \\
Autoinfection & $\delta_{1}$ & 52.15 & $(42.39,61.91)$ & & 2.80 & $(2.64,2.95)$ \\
& $\delta_{2}$ & 25.23 & $(23.48,26.99)$ & & 4.16 & $(3.97,4.35)$ \\
Spread & $\gamma_{1}$ & 17.94 & $(15.40,20.48)$ & & 0.39 & $(0.30,0.47)$ \\
& $\gamma_{2}$ & 23.30 & $(20.25,26.36)$ & & 0.49 & $(0.31,0.67)$ \\
Dispersal & $a_{1}$ & 0.52 & $(0.43,0.61)$ & & 0.30 & $(0.21,0.39)$ \\
& $a_{2}$ & 1.25 & $(1.09,1.42)$ & & 0.66 & $(0.30,1.01)$ \\
\hline
\end{tabular}

a Autoinfection refers to within-yard transmission, spread refers to betweenyard transmission, and dispersal refers to a range of dispersal.

b The parameter subscript 1 indicates R6 cultivars, which receive inoculum capable of causing disease from only V6-virulent sources of Podosphaera macularis. Subscript 2 indicates non-R6 cultivars, which receive inoculum capable of causing disease from both V6 and non-V6 virulent sources. 
errors are calculated as $N^{-1} \sum_{i}\left|Y_{i}-n_{i} \hat{p}_{i}\right|$. In addition, the classification accuracy was assessed for each held-out year by reselecting the threshold from remaining data and comparing observed disease status to whether estimated disease probability was above or below the edge threshold. Mean absolute errors varied depending on the years used to estimate the parameters, ranging from 0.08 to 0.19 when considering all hop yards in the held-out year and 0.17 to 0.25 when error calculations were restricted to only yards where disease was present or the yard was predicted to be at risk as a result of dispersal. Similarly, overall classification accuracy of the model was sensitive to the years used to estimate the parameters.

Over all years and considering all yards, mean absolute differences between observed and expected disease incidence were 0.096 for the May to June transition and 0.083 for the June to July transition (Fig. 1; Supplementary Figs. S2 and S3). In general, expected disease according to the fitted model was within $20 \%$ of observed disease, and outside of this range underprediction was slightly more frequent (the tail was slightly heavier in the positive direction) (Fig. 1). The areas under the ROC curves used to calculate threshold values for graph formation were also considered as a

TABLE 5. Fold-by-fold error and classification metrics from the holdout procedure: mean absolute errors (MAEs), mean absolute errors calculated only for infected or at risk fields (restricted MAEs), sensitivity, and specificity

\begin{tabular}{lcccc}
\hline Held-out year & Restricted MAE & MAE & Sensitivity & Specificity \\
\hline $\begin{array}{l}\text { May to June } \\
2014\end{array}$ & 0.242 & 0.155 & 0.582 & \\
2015 & 0.164 & 0.078 & 0.400 & 0.867 \\
2016 & 0.187 & 0.086 & 0.233 & 1.000 \\
2017 & 0.176 & 0.076 & 0.435 & 0.951 \\
$\quad$ June to July & & & & \\
2014 & 0.158 & 0.138 & 0.912 & 0.485 \\
2015 & 0.157 & 0.083 & 0.939 & 0.765 \\
2016 & 0.104 & 0.065 & 0.800 & 0.716 \\
2017 & 0.088 & 0.055 & 0.558 & 0.716 \\
\hline
\end{tabular}

generic measure of classification accuracy and indicated adequate performance (Fig. 1).

Sensitivity analysis. Sensitivity analysis indicated varying effects of model input variables on predicted disease. The input variables (equation 2) were distance, wind run, and source strength (disease incidence scaled by yard area [Supplementary Fig. S4]). With parameters fixed at their estimated values for each time transition and each source-target network, varying each possible pair of input variables while holding the third at a representative value for the given month produced a surface showing the sensitivity of expected disease probability to combinations of the input variables (Fig. 2).

Among the input variables, log-odds of disease risk changed most markedly based on source strength and distance. During the May to June transition, examination of log-odds isopleths indicated that the greatest risk of disease was associated with source fields with severe disease and within $1 \mathrm{~km}$, but with decreasing risk with distance that depended on the cultivar susceptibility group. The shapes of the isopleths were qualitatively similar for the June to July transition, although the $\log$-odds of estimated disease risk for all variables were more than an order of magnitude less compared with the May to June transition. This finding is consistent with the substantial reduction in the estimates of the disease spread parameters $(\gamma)$ in the June to July transition compared with May to June.

Network inference. Network visualizations and spatial predictions. Network visualizations of the growing region indicated variation in connectivity between time periods as well as between cultivar susceptibility classes (Fig. 3). The majority of edges corresponded to low-probability influences, since the thresholds allowed that any increase in disease probability $\left(p_{k i}\right.$, defined in equation 10) exceeding 0.002 in the May to June transition or 0.001 in the June to July transition attributable to a single source resulted in an edge. For example, only $9 \%$ of the 206 edges formed in the May to June transition of 2014 corresponded to increases in disease probability exceeding 0.1 , and only $3 \%$ corresponded to increases exceeding 0.2 . Thus, strong connectivity was extremely sparse, even when there was ample weak connectivity.
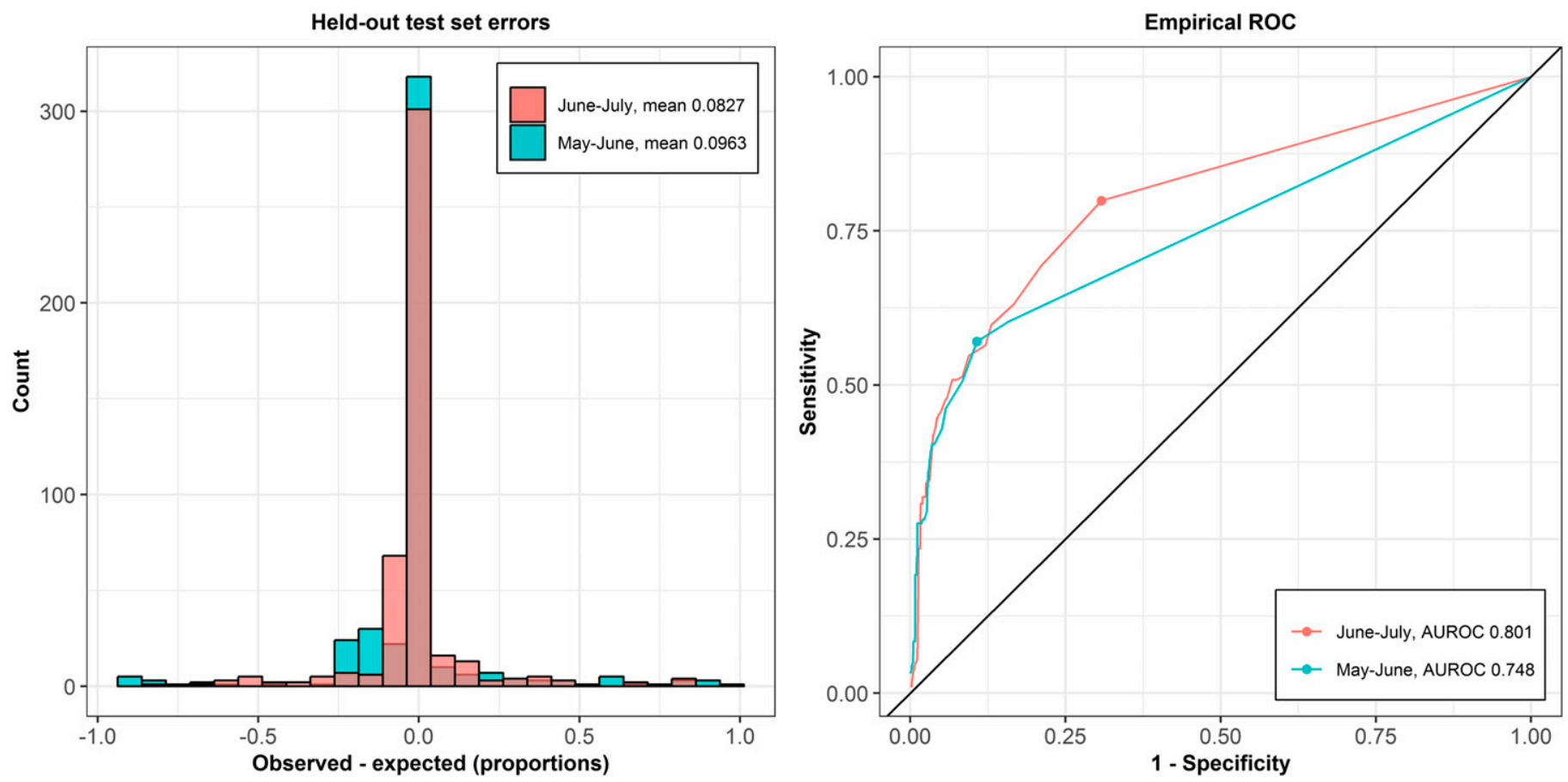

Fig. 1. Error quantification plots. The left panel is a histogram of mean absolute differences between observed and expected disease across all four folds of the holdout procedure. The right panel shows empirical receiver operating characteristic (ROC) curves resulting from varying the threshold for forming an edge between hop yards. The area under the ROC curve (AUROC) indicates overall classification accuracy for prediction of disease presence or absence. The diagonal line is the line of no discrimination, where predictions of disease presence or absence are no better than chance. Points on the line indicate the sensitivity and specificity of the models at the thresholds selected in this research. 
Spatial predictions of disease based on spread from observed sources showed much greater areas with nonnegligible disease predictions for R6 cultivars compared with non-R6 cultivars, and there was a general diminution of these areas in the later time transition (Fig. 3; Supplementary Figs. S5, S6, and S7). The irregularity of the contours of these areas was indicative of the impact of wind run on expected disease levels according to the model.

Degree centralities and highly connected nodes. Over all years and considering both cultivar groups (R6 and non-R6 cultivars), the distribution of node degree centrality was right skewed with most yards having no outward-directed edges in either month (Fig. 4). A total of 29 yards had at least one outward-directed edge in the May to June transition for some year and 105 in the June to July transition. In both transition periods, the maximum outward centrality was 24 . There were more yards with nonzero centralities in the June to July transition compared with May to June, although the mean degree centrality was less in June to July (7.1) compared with May to June (8.4). Over both months, yards with R6 cultivars had mean degree centrality of 8.2 , whereas yards with non-R6 cultivars had mean degree centrality of 6.3 .

A descriptive analysis of the outward degree centralities (number of outward-facing edges associated with each node, equation 11) for each graph and subsequent examination of highly connected yards revealed that strongly influential sources in disease spread tended to be yards located within short distances (roughly 1 to $2 \mathrm{~km}$ ) of the nearest $10 \%$ of yards (Fig. 4). There was an association between source strength and node degree for yards that had a large node degree, although a large source strength was not consistently associated with node degree centrality.

Examination of each of five yards with the greatest node degree centrality in each year, cultivar group, and time period indicated some tendencies of the yards most central to the networks. Among these 80 yards, 20 had node degree 0 (as did all other nodes) and were ignored. Among the remaining 60 yards, these yards were found on six farms, with three farms containing 54 (90\%) of the most highly connected nodes. The frequency of occurrence of highly central yards was overrepresented on these three farms based on the total number of yards on these farms relative to the entire data set $(31.0 \%)$. The cultivar Nugget also was overrepresented, being associated with $58.3 \%$ of the most central nodes versus $17.1 \%$ of yards overall. Correspondingly, in the yards central to the networks, the race of the initial race of the fungus detected possessed R6virulence in $60 \%$ of yards, compared with $31.6 \%$ of yards in the overall data set. Central nodes also were characterized as having far more severe powdery mildew, on average, compared with the total population of yards. In June and July, the mean incidence of plants with powdery mildew was 6.6 and $5.5 \%$ in the overall data set, respectively. In contrast, disease incidence was 50.7 and $52.5 \%$ in the same months in yards central to the networks. Highly central yards in June and July were more likely to have had a flag shoot in April or May (28.3\% of yards) compared with the entire data set $(2.8 \%)$.

\section{DISCUSSION}

Visualizations of model-derived quantities as a network yielded several important insights. In all years, most edges were formed between hop yards on the same or adjacent farms, and comparatively rarely were edges formed over distances greater than approximately $10 \mathrm{~km}$ (Fig. 3). That is, disease spread was mostly localized. Figures of local subregions indicate that spread of powdery mildew was complex, directional based on prevailing

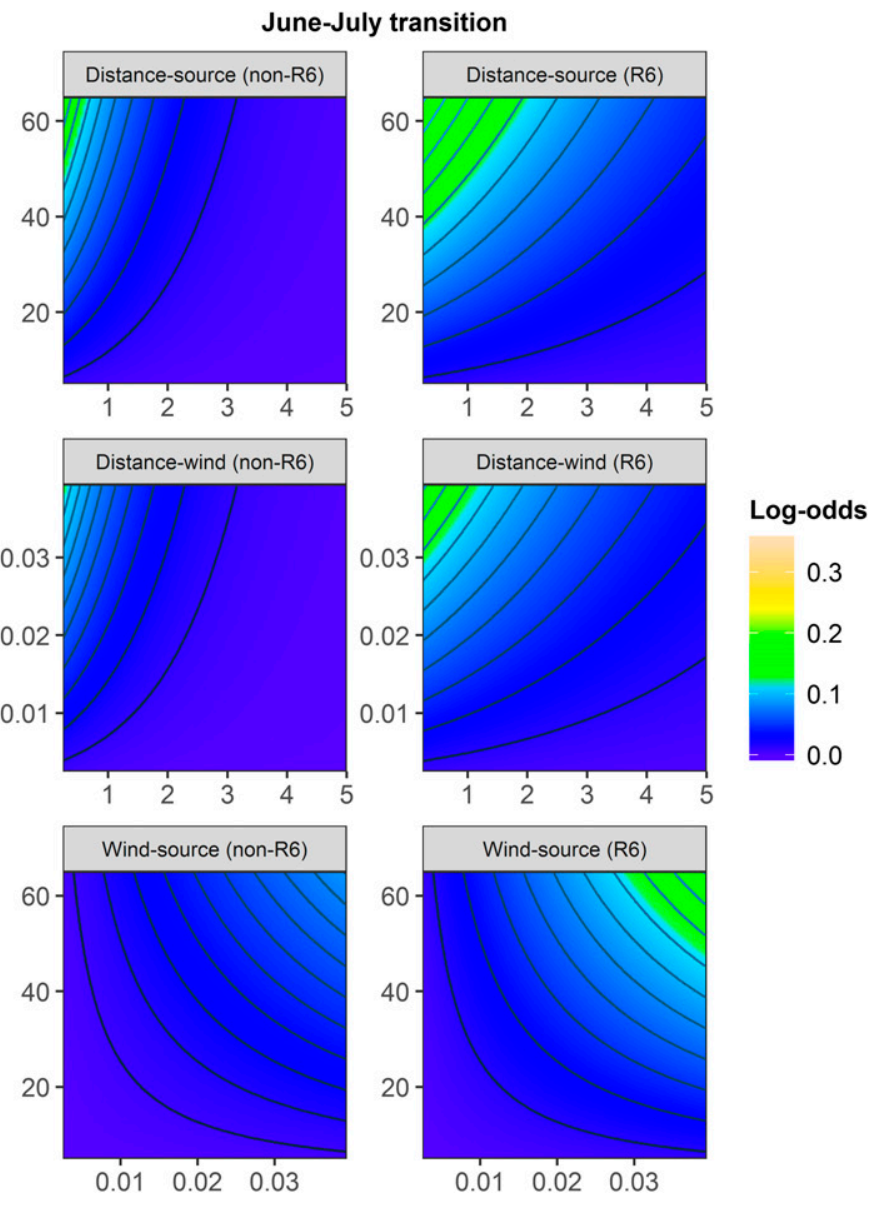

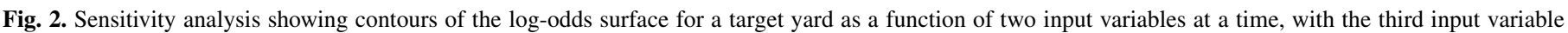

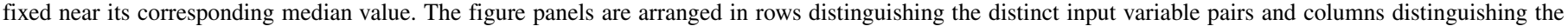
transition and source-target network. Units are kilometers for distance, kilometers/second for wind, and the percentage of diseased plants for source. 
winds, and associated with source strength of a hop yard in the localized vicinity (i.e., within $2 \mathrm{~km}$; Fig. 4). For example, among R6 cultivars in the May to June transition in 2014, a single heavily diseased field was predicted to influence disease in 10 other hop yards (Fig. 3). Comparatively rarely were strong edges formed between fields.

There are notable differences in connectivity and aggregate disease risk between the distinct cultivar susceptibility classes, with aggregate disease risk greater for cultivars that possess R6 than those that do not. Based on this data set and analysis, the presence of the defeated R-gene R6 does not lead to an overall reduction in disease risk given all other variables present, although measurable reductions in pathogenic fitness exist between the races of the fungus (Wolfenbarger et al. 2016). Of particular note, there is more connectivity and there are more edges spanning greater distances in the networks representing the influence of the R6-virulent races of the fungus on disease risk of cultivars resistant to non-R6-virulent races (Fig. 3). There are several plausible reasons why this may be, such as enhanced dispersal capabilities of R6-virulent races or, more likely, connectivity of yards planted to cultivars with R6. It is not possible with the present data set to quantitatively account for cultivar susceptibility within those possessing R6 or not. Qualitatively, however, some of the cultivars most susceptible to powdery mildew happen to possess R6 (Gent et al. 2015). Therefore, inoculum production and also infection efficiency of R6-virulent races may contribute to the differences in connectivity between cultivar susceptibility classes.

The spatialized predictions of disease risk attributable to dispersal as depicted in Figure 3 are counterintuitive upon first examination. Pathogen source strength is a primary determinant of dispersal that profoundly influences the likelihood of disease at some distance away from a source (Fig. 2), yet the disease risk maps
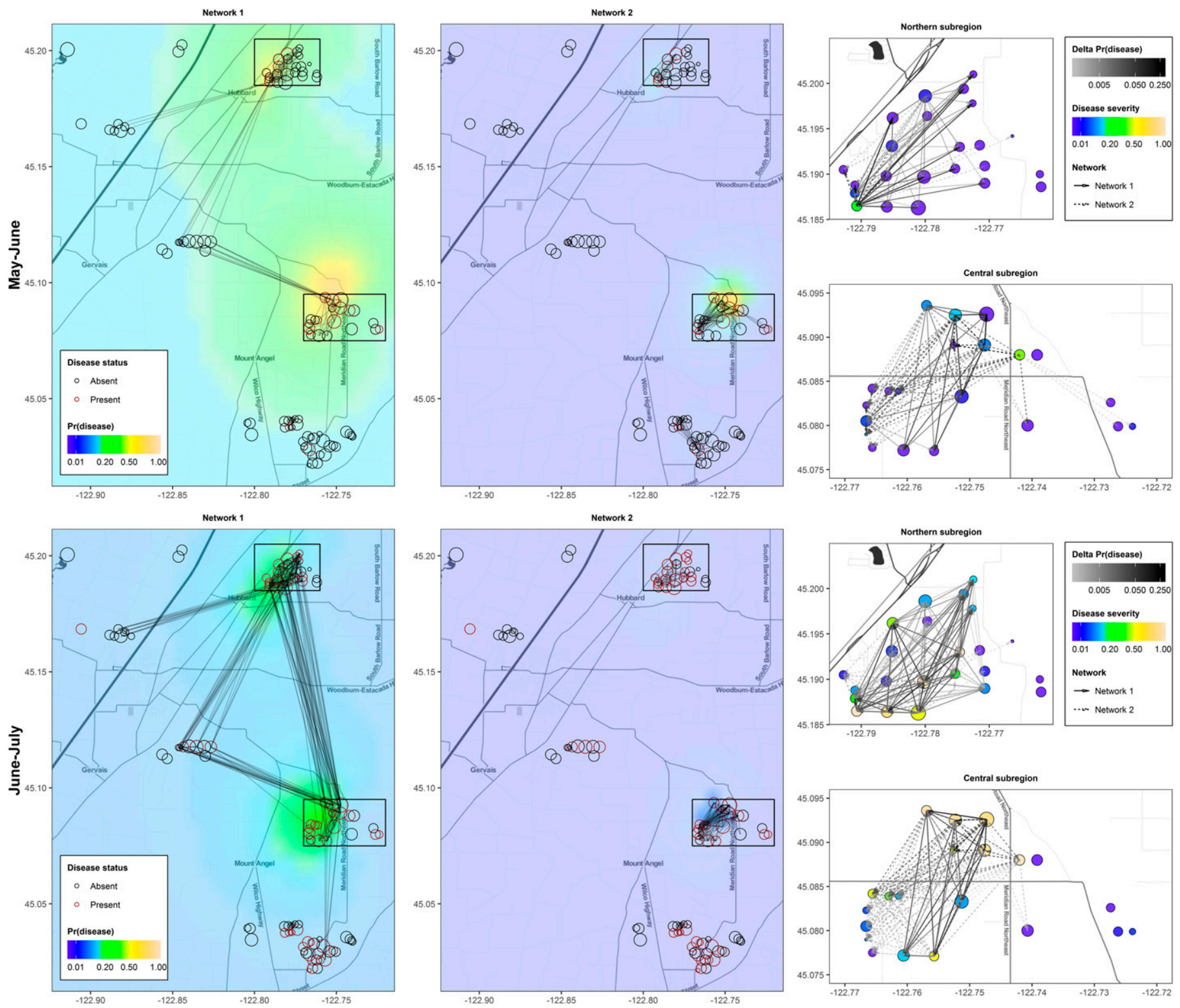

Fig. 3. Superposition of network visualizations and surface interpolated from pointwise spatial predictions of disease attributable to spread on 2014 data for the May to June transition (top row) and the June to July transition (bottom row). The full spatial region plots (27.6 km across the diagonal) show networks and predictions separately for each cultivar susceptibility class (left and center panels of each row). The rightmost panels show local detail for subregions with observed disease levels on the same color scale as the spatial predictions and distinct edge types for each cultivar susceptibility class. Subregion locations are indicated by boxes on the full spatial region plots. Edge transparency and darkness are proportional to the strength of influence $\left(\Delta p_{k i}\right.$ as defined in equation 9$)$ and point sizes are proportional to yard area in all plots. Note that edges appear darker in the June to July transition but this is attributable to overlapping of the more numerous lines. Details of the edges and edge weights can be discerned more clearly in the maps of the subregions. 
in Figure 3 appear to show the opposite association during the May to June transition compared with June to July when disease is present in more yards (Table 1). Furthermore, plant height is greater in June to July than May to June, which one would predict to increase the conidia escape fraction of inoculum produced in the upper levels of the canopy (Aylor 2017). These apparent discrepancies with biological expectations are resolved by consideration of the varying model parameter estimates for each time transition period. As shown in Table 4, the values of $\delta, \gamma$, and $\alpha$ are less in June to July versus May to June, although the relative magnitudes of the spread parameters $(\gamma)$ compared with autoinfection parameters $(\delta)$ decrease markedly. The reduction in magnitudes of autoinfection and spread parameters as the season progresses would seem to suggest that autoinfection and spread are less prevalent later in the season. However, this is not necessarily true, as the difference in magnitudes may be partly attributable to the observed increase in source strength per yard (Table 1), because an increase in source strength could be offset by a reduction in both $\delta$ and $\gamma$ parameters for a fixed predictor value in equation 2 . Thus, the dramatic difference in estimates between the two transitions does not necessarily imply a corresponding reduction in the true contribution of autoinfection and disease spread.

Furthermore, since the parameters quantify the influence of autoinfection and spread conditional on one another, one needs to consider how increased source abundance over time might influence quantification of spread-adjusted autoinfection and autoinfectionadjusted spread. In light of the caveat regarding parameter magnitudes, it is helpful to consider the change in relative magnitudes of the parameters describing spread and autoinfection: the ratios of these parameters change from 2.91 to 7.18 (for R6 cultivars, $\frac{\delta_{1}}{\gamma_{1}}$ ) and from 1.08 to 8.49 (for non-R6 cultivars, $\frac{\delta_{2}}{\gamma_{2}}$ ) in the May to June transition compared with the June to July transition (Table 4). Thus, while the change in disease incidence among fields appears qualitatively less influenced by both within-field disease spread (as represented by $\delta$ ) and disease in other fields in aggregate (as represented by $\gamma$ ) during June to July compared with May to June based on the difference in estimates, it also appears relatively more influenced by autoinfection than spread in the later transition. However, considering the conditional interpretation of these parameters (Table 3), this phenomenon might be partly attributable to the increase in the abundance of sources across all yards in the area of interest. Considering that as many as $50 \%$ of yards are diseased in June compared with at most $10 \%$ in May (Table 1), and that the proportion of yards with disease does not change dramatically in July, a much greater amount of observed disease in July is explicable by autoinfection in the model. This might explain why the contribution of spread to disease risk after accounting for autoinfection appears almost negligibly small. As such, the change in relative contributions of autoinfection and spread does not necessarily imply that disease is no longer spreading late in the season. Close inspection of Figure 3 shows that although edges are more numerous in the network in the June to July transition compared with May to June, edge weights also tend to be weaker.

The present study relied on observations of disease to infer dispersal and estimate disease risk. A disadvantage of using observed disease incidence to estimate risk is the discrepancy between risk and incidence in an observational study (Ostfeld et al. 2005). This is a weakness of our approach. As previously noted, confounding might partly account for the dramatic differences in magnitudes of spread and autoinfection parameters between transition periods. Two such confounding factors are directly observable in the data: both the source strength per affected yard and source abundance among all yards increase as the season progresses, as shown in Table 1.

A further source of potential confounding is that the hop yards assessed were all managed, to varying extents, to reduce levels of powdery mildew through various cultural practices and fungicide application. The frequency of application and specific fungicide applied generally vary between growers, but also over the season. Again, the modeling framework described here did not explicitly consider grower management intervention or inherent differences in susceptibility of individual cultivars, potentially introducing random error or spatial biases into the analyses (Ostfeld et al. 2005). Random error is reflected in the variance of the estimated model parameters, but spatial bias is more difficult to assess, as this could be completely confounded with hop yard location and management interventions by the grower. Furthermore, we assume that disease spread is entirely attributable to windborne dispersal and limited to the hop yards within the spatial extent of the study. Although attempts were made to include all hop yards where powdery mildew historically has been most problematic and those yards where the pathogen was most likely to overwinter, one cannot know with certainty if exogenous inoculum from other yards was present.
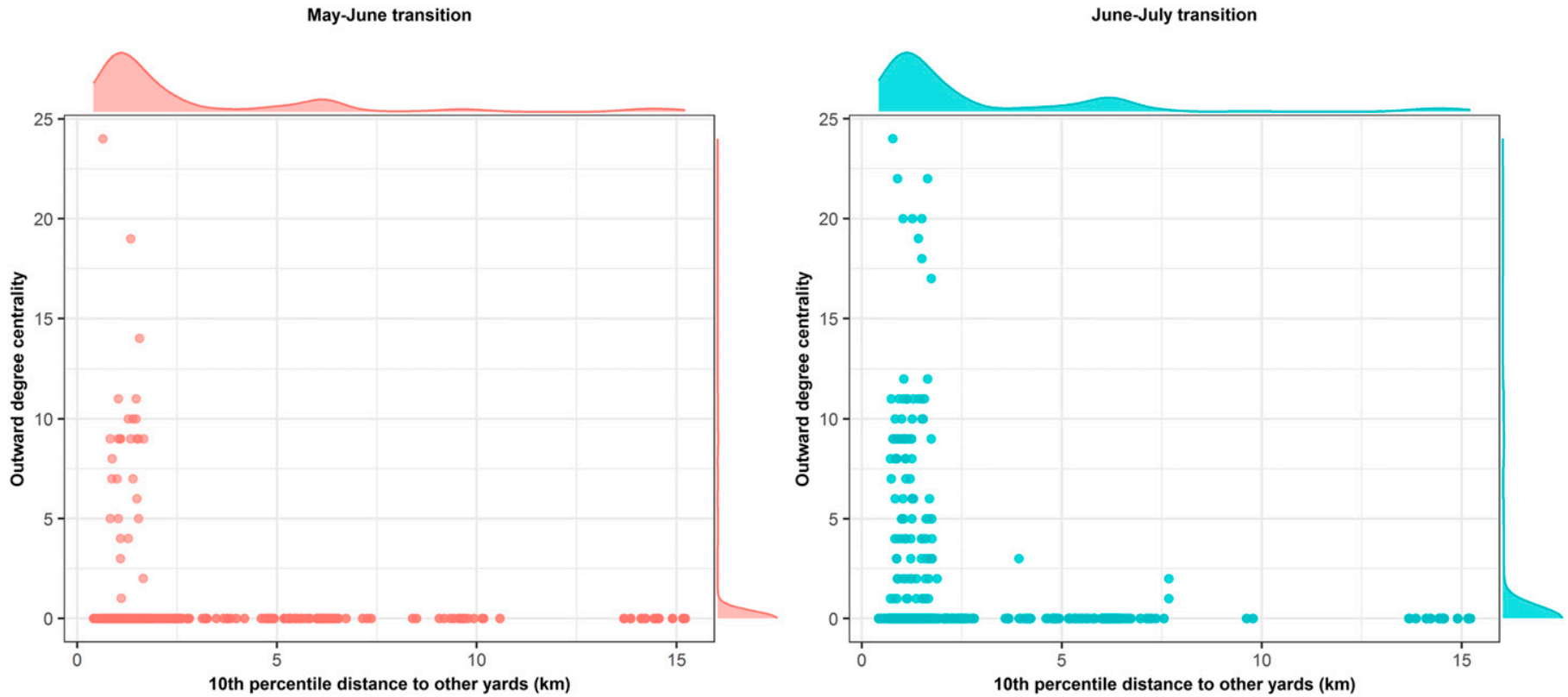

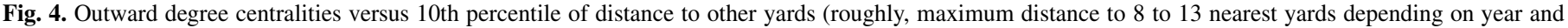
month), by month, with marginal histograms. 
However, the intercept term, $\beta$, captures the baseline risk of disease attributable to variables not considered explicitly in the model, which would encompass inoculum arriving from other yards not included in the sampling. Also, in reality, some spread of inocula by human-mediated means, such as workers or field scouts, is possible (Mahaffee et al. 2009) but assumed to be insignificant compared with aerial dispersal of conidia.

This research extends the network transmission models of Sutrave et al. (2012) and Sanatkar et al. (2015) in several ways that were not possible within their simulation-type approaches. First, the model framework is not constrained to only SI forms of data and observations. The present analyses were based on binomial disease incidence data but the model is generalizable to other data forms (e.g., continuous, discrete) following different probability distributions. Second, the functional form of the predictor captures not only risk factors for disease development and spread owing to connectivity in the network but also to baseline disease risk and risk owing to disease increase within a field. Although we considered one functional form, many other variant forms can be explored easily and tested explicitly for goodness of fit. Third, the model output is probabilistic and amenable to hypothesis testing of disease spread at multiple spatial scales and at new locations. While we have applied the model in the specific case of hop powdery mildew to understand spread at the regional scale, predictions at other distances are feasible. Simulationbased approaches, in contrast, are constrained to extant locations within the network and not generalizable in these ways. Fourth, the model is predictive. Fifth, the approach used here does not require all nodes to be present at all time points, although the quality of fit depends on having a set of nodes at each time point that adequately represents local sources of inoculum. Therefore, new knowledge of fields or updating to consider new plantings can be accommodated in the model for the next time transition. Because of these attributes, network inference is greatly simplified and essentially is a byproduct of the model predictions.

The functional form of the present model retains variables that are central to processes associated with disease development as a result of dispersal. Mechanistic models of airborne pathogen dispersal comprise multiple, interrelated components: namely (i) source strength, (ii) wind direction, (iii) airborne travel time, (iv) dilution of the spore cloud by turbulence, and (v) attrition of spores caused by mortality or physical removal by deposition (Aylor 2017). The simple model of dispersal presented here incorporates covariates associated with source strength and wind direction. Components related to airborne travel time, dilution, and attrition of viable inoculum are not considered explicitly, although distance between nodes may be a correlate of the variables related to these processes.

The model also attempts to separately quantify disease risk attributable to within-yard spread and additional undefined, baseline risks not captured by the other explanatory variables. In this aspect, the model estimates disease development attributable to all potential sources of inoculum, including unobserved sources. Predictions of observed disease incidence captured trends in disease over all hop yards but in some instances yielded poor predictions of individual yards. This appears to be related to under- or overprediction of disease related to cultivar susceptibility or when primary inoculum was associated with occurrence of a flag shoot. Numerous, interacting factors influence disease levels in a given field, such as fungicide use and timing, plant growth dynamics, and local weather (Mahaffee et al. 2009). Simulation models are needed to best represent these processes (Calonnec et al. 2008). In the present model, within-field disease increase is approximated only crudely with a single parameter. Although this is clearly an oversimplification, prediction errors associated with autoinfection within a yard are perhaps least consequential for management decisions intended to capture the earliest generations of the pathogen. More serious errors are those related to failure to predict the initial onset of disease attributable to dispersal because these errors may lead erroneously to not applying control measures when needed.
In large and small networks, final epidemic size depends on the node from which an epidemic is started (Pautasso et al. 2010). Empirical data and simulation studies point to the critical importance of the conditions of the initial disease focus for epidemic spread with organisms capable of long-distance dispersal (Estep et al. 2014; Mundt and Sackett 2012; Mundt et al. 2013; Ojiambo et al. 2017; Severns et al. 2014, 2015, 2018; Simberloff 2009; Xu and Ridout 1998). This association is most pronounced for organisms where dispersal is described by "heavy-tailed" dispersal kernels, such as the power law, which are not exponentially bound and produce accelerating epidemic fronts (Ferrandino 1993; Mundt et al. 2009a, b). Evidence of the importance of initial epidemic conditions on disease spread is evident in multiple powdery mildew pathosystems, as the occurrence and severity of powdery mildew diseases are influenced by overwintering inoculum dose at scales ranging from individual plants to metapopulations (Moyer et al. 2014; Soubeyrand et al. 2009; Tack and Laine 2014). Depending on the connectivity of the population, failure to overwinter may result in local extinction of the pathogen (Tack and Laine 2014) and influence final epidemic size (Pautasso et al. 2010).

There is evidence of an association between conditions of the initial outbreak and epidemic conditions in the present analysis. The yards with greatest node degree centrality were qualitatively characterized as being located within a nearly contiguous arrangement of other yards, planted to a susceptible cultivar (most often Nugget), were initially infected by a race of $P$. macularis possessing R6 virulence, and had relative severe disease in the preceding time period. Such yards typically were the most central nodes in the network in both time periods and were responsible for disease spread to numerous other yards in spring. Thus, node centrality was associated with variables related to source strength and presence of susceptible hosts in and near the initial focus.

The profile of yards central to the network provides a target for prioritizing management intervention. Of the correlates of node degree centrality identified, reduction in the incidence of flag shoots is probably the risk factor growers can target most easily and preventatively. Bud perennation that results in flag shoot development is a rare event in the western United States and occurs only in a subset of yards, but the risk of flag shoot occurrence can be estimated probabilistically (Gent et al. 2019). Based on the present research, elimination of early season inoculum in a subset of yards across a relatively small area, specifically the most central nodes in the network harboring races of $P$. macularis with R6 virulence, could retard powdery mildew development and spread. The means to eliminate overwintering inoculum exist, as cultural practices such as mechanical pruning greatly reduce the risk of flag shoot development (Gent et al. 2008, 2012, 2019; Probst et al. 2016). The spatial extent at which primary inoculum needs to be eliminated is somewhat uncertain based on the present analysis. However, in a dense planting of yards, elimination of primary inoculum within a $2-\mathrm{km}$ radius seems to be the minimum for mitigating hop powdery mildew in the early phases of the epidemic. Larger distances may need to be managed if yards are planted contiguously, or nearly so, over a larger area. This is common in certain production regions and in agricultural landscapes in general (Margosian et al. 2009). In these circumstances, control measures that eliminate primary inoculum may need to be deployed at distances proportional to the density of the host planting.

Scaling of management actions to match the dispersal characteristics of a pest is an important concept in integrated pest management systems (Irwin 1999), as effective control requires reducing primary inoculum emanating from outside the field and secondary inoculum driving autoinfection within the field (Aylor 1999; Bergamin Filho et al. 2016). The models and analysis here could inform both strategic and tactical decisions about disease management. Strategically, yards that are highly central to epidemics are logical targets for intensified management, as noted previously. Besides cultural practices to eliminate primary inoculum, yards central to the 
network may be targeted for replanting with resistant cultivars if such yards are persistently central over multiple years. Furthermore, the effectiveness of such strategic management actions could be evaluated by simulation given the models developed here.

Within a growing season, predicted dispersal between yards could inform tactical decision making. Making informed decisions about the appropriate timing and intensity of management actions requires knowledge of both sources of inoculum, but pathogen dispersal across fields is a process that is difficult to learn based on experience or simple heuristics. The dispersal model developed herein, and the resulting implications of the model for disease spread within a network framework, inform uncertain situations that growers routinely face. This is important for disease management because the timing of the first fungicide application of the season is paramount to the success of a grower's entire management program for powdery mildew (Gent et al. 2015; Mahaffee et al. 2009). Thus, the models developed here could serve as the basis for a useful decision aid in this pathosystem (Gent et al. 2013). Provision of the necessary disease scouting and pathogen race data over a large geographic area will be a main limitation.

\section{ACKNOWLEDGMENTS}

This work was made possible by the work of many individuals that assisted with disease ratings. We thank Karen Garrett and John Hernandez Nopsa for their ideas and discussions on this project. Chris Mundt and Sarah Emerson provided helpful comments that improved this paper.

\section{LITERATURE CITED}

Anderson, R. M., and May, R. M. 1992. Infectious Diseases of Humans: Dynamics and Control. Oxford University Press, Oxford, UK.

Aylor, D. E. 1999. Biophysical scaling and the passive dispersal of fungal spores: Relationship to integrated pest management strategies. Agric. For. Meteorol. 97:275-292.

Aylor, D. E. 2017. Aerial Dispersal of Pollen and Spores. American Phytopathological Society, St. Paul, MN.

Bajardi, P., Barrat, A., Natele, F., Savini, L., and Colizza, V. 2011. Dynamical patterns of cattle trade movements. PLoS One 6:e19869.

Bergamin Filho, A., Inoue-Nagata, A. K., Bassanezi, R. B., Belasque, J., Jr., Amorim, L., Macedo, M. A., Barbosa, J. C., Willocquet, L., and Savary, S. 2016. The importance of primary inoculum and area-wide disease management to crop health and food security. Food Secur. 8:221-238.

Buddenhagen, C. E., Hernandez Nopsa, J. F., Andersen, K. F., Andrade-Piedra, J., Forbes, G. A., Kromann, P., Thomas-Sharma, S., Useche, P., and Garrett, K. A. 2017. Epidemic network analysis for mitigation of invasive pathogens in seed systems: Potato in Ecuador. Phytopathology 107:1209-1218.

Calonnec, A., Cartolaro, P., Naulin, J.-M., Bailey, D., and Langlais, M. 2008. A host-pathogen simulation model: Powdery mildew of grapevine. Plant Pathol. 57:493-508.

Chadès, I., Martin, T. G., Nicol, S., Burgman, M. A., Possingham, H. P., and Buckley, Y. M. 2011. General rules for managing and surveying networks of pests, diseases, and endangered species. Proc. Natl. Acad. Sci. USA 108: 8323-8328.

Del Ponte, E. M., Pethybridge, S. J., Bock, C. H., Michereff, S. J., Machado, F. J., and Spolti, P. 2017. Standard area diagrams for aiding severity estimation: Scientometrics, pathosystems and methodological trends in the last 25 years. Phytopathology 107:1161-1174.

Estep, L. K., Sackett, K. E., and Mundt, C. C. 2014. Influential disease foci in epidemics and underlying mechanisms: A field experiment and simulations. Ecol. Appl. 24:1854-1862.

Eubank, S., Guclu, H., Anil Kumar, V. S., Marathe, M. V., Srinivasan, A., Toroczkai, Z., and Wang, N. 2004. Modelling disease outbreaks in realistic urban social networks. Nature 429:180-184.

Ferrandino, F. J., 1993. Dispersive epidemic waves: I. Focus expansion within a linear planting. Phytopathology 83:795-802.

Firester, B., Shtienberg, D., and Blank, L. 2018. Modelling the spatiotemporal dynamics of Phytophthora infestans at a regional scale. Plant Pathol. 67: 1552-1561.

Garrett, K. A., Alcalá-Briseño, R. I., Anderson, K. F., Buddenhagen, C. E., Choudhury, R. A., Fulton, J. C., Hernandez Nopsa, J. F., Poudel, R., and Xing, Y. 2018. Network analysis: A systems framework to address grand challenges in plant pathology. Annu. Rev. Phytopathol. 56:25.1-25.22.
Garrett, K. A., Andersen, K. F., Asche, F., Bowden, R. L., Forbes, G. A., Kulakow, P. A., and Zhou, B. 2017. Resistance genes in global crop breeding networks. Phytopathology 107:1268-1278.

Gent, D. H., Claassen, B. J., Twomey, M. C., Wolfenbarger, S. N., and Woods, J. L. 2018. Susceptibility of hop crown buds to powdery mildew and its relation to perennation of Podosphaera macularis. Plant Dis. 102: 1316-1325.

Gent, D. H., Mahaffee, W. F., McRoberts, N., and Pfender, W. F. 2013. The use and role of predictive systems in disease management. Annu. Rev. Phytopathol. 51:267-289.

Gent, D. H., Mahaffee, W. F., Turechek, W. W., Ocamb, C. M., Twomey, M. C., Woods, J. L., and Probst, C. 2019. Risk factors for bud perennation of Podosphaera macularis on hop. Phytopathology 109:74-83.

Gent, D. H., Massie, S. T., Twomey, M. C., and Wolfenbarger, S. N. 2017. Adaptation to partial host resistance in the cultivar Cascade by Podosphaera macularis. Plant Dis. 101:874-881.

Gent, D. H., Nelson, M. E., Gadoury, D. M., Gevens, A. J., and Hausbeck, M. K. 2015. Powdery mildew. Pages 25-29 in: Field Guide for Integrated Pest Management in Hops, 3rd ed. S. B. O'Neal, D. B. Walsh, and D. H. Gent, eds. Washington State University, Pullman, WA.

Gent, D. H., Nelson, M. E., George, A. E., Grove, G. G., Mahaffee, W. F., Ocamb, C. M., Barbour, J. D., Peetz, A., and Turechek, W. W. 2008. A decade of hop powdery mildew in the Pacific Northwest. Plant Health Prog. 9:33.

Gent, D. H., Nelson, M. E., Grove, G. G., Mahaffee, W. F., Turechek, W. W., and Woods, J. L. 2012. Association of spring pruning practices with severity of powdery mildew and downy mildew on hop. Plant Dis. 96: 1343-1351.

Goffman, W., and Newill, V. A. 1964. Generalization of epidemic theory. Nature 204:225-228.

Grassberger, P. 1983. On the critical behavior of the general epidemic process and dynamical percolation. Math. Biosci. 63:157-172.

Hernandez Nopsa, J. F., Daglish, G. J., Hagstrum, D. W., Leslie, J. F., Phillips, T. W., Scoglio, C., Thomas-Sharma, S., Walter, G. H., and Garrett, K. A. 2015. Ecological networks in stored grain: Key postharvest nodes for emerging pests, pathogens, and mycotoxins. Bioscience 65:985-1002.

Irwin, M. E. 1999. Implications of movement in developing and deploying integrated pest management strategies. Agric. For. Meterol. 97:235-248.

Isella, L., Stehle, J., Barrat, A., Cattuto, C., Pinton, J., and Van den Broeck, W. 2011. What's in a crowd? Analysis of face-to-face behavioral networks. J. Theor. Biol. 271:166-180.

Jarvis, W. R., Gubler, W. D., and Grove, G. G. 2012. Epidemiology of powdery mildews in agricultural pathosystems. Pages 169-199 in: The Powdery Mildews, A Comprehensive Treatise. R. Belanger, W. R. Bushnell, A. J. Did, and T. L. W. Carver, eds. American Phytopathological Society, St. Paul, MN

Jeger, M. J., Pautasso, M., Holdenrieder, O., and Shaw, M. W. 2007. Modelling disease spread and control in networks: Implications for plant sciences. New Phytol. 174:279-297.

Keeling, M. J., and Rohani, P. 2011. Modeling Infectious Diseases in Humans and Animals. Princeton University Press, Princeton, NJ.

Kermack, W. O., and McKendrick, A. G. 1991. Contributions to the mathematical theory of epidemics I. Bull. Math. Biol. 53:33-55.

Liu, Z., Lai, Y., and Nong, Y. 2003. Propagation and immunization of infection on general networks with both homogeneous and heterogeneous components. Phys. Rev. E 67:031911.

Liyanage, A. S., and Royle, D. J. 1976. Overwintering of Sphaerotheca humuli, the cause of hop powdery mildew. Ann. Appl. Biol. 83:381-394.

Mahaffee, W. F., Engelhard, B., Gent, D. H., and Grove, G. G. 2009. Powdery mildew. Pages 25-31 in: Compendium of Hop Diseases and Pests. W. M. Mahaffee, S. J. Pethybridge, and D. H. Gent, eds. American Phytopathological Society, St. Paul, MN.

Margosian, M. L., Garrett, K. A., Hutchinson, J. M. S., and With, K. A. 2009. Connectivity of the American agricultural landscape: Assessing the national risk of crop pest and disease spread. Bioscience 59:141-151.

Meentemeyer, R. K., Haas, S. E., and Václavìk, T. 2012. Landscape epidemiology of emerging infectious diseases in natural and human altered ecosystems. Annu. Rev. Phytopathol. 50:379-402.

Meyer, M., Cox, J. A., Hitchings, M. D. T., Burgin, L., Hort, M. C., Hodson, D. P., and Gilligan, C. A. 2017. Quantifying airborne dispersal routes of pathogens over continents to safeguard global wheat supply. Nat. Plants 3: 780-786.

Moyer, M. M., Gadoury, D. M., Wilcox, W. F., and Seem, R. C. 2014. Release of Erysiphe necator ascospores and impact of early-season disease pressure on Vitis vinifera fruit infection. Am. J. Enol. Vitic. 65:315-324.

Mundt, C. C., and Sackett, K. E. 2012. Spatial scaling relationships for spread of disease caused by a wind-dispersed plant pathogen. Ecosphere 3:art24.

Mundt, C. C., Sackett, K. E., Wallace, L. D., Cowger, C., and Dudley, J. P. 2009a. Aerial dispersal and multiple-scale spread of epidemic disease. EcoHealth 6:546-552. 
Mundt, C. C., Sackett, K. E., Wallace, L. D., Cowger, C., and Dudley, J. P. 2009b. Long distance dispersal and accelerating waves of disease: Empirical relationships. Am. Nat. 173:456-466.

Mundt, C. C., Wallace, L. D., Allen, T. W., Hollier, C. A., Kemerait, R. C., and Sikora, E. J. 2013. Initial epidemic area is strongly associated with the yearly extent of soybean rust spread in North America. Biol. Invasions 15:1431-1438.

Newman, M. E. J. 2010. Networks: An Introduction. Oxford University Press, Oxford, UK.

Ojiambo, P. S., Gent, D. H., Mehra, L. K., Christie, D., and Magarey, R. 2017. Focus expansion and stability of the spread parameter estimate of the power law model for dispersal gradients. PeerJ 5:e3465.

Ostfeld, R., Glass, G., and Keesing, F. 2005. Spatial epidemiology: An emerging (or re-emerging) discipline. Trends Ecol. Evol. 20:328-336.

Pastor-Satorras, R., and Vespignani, A. 2001. Epidemic spreading in scale-free networks. Phys. Rev. Lett. 86:3200.

Pautasso, M., and Jeger, M. J. 2014. Network epidemiology and plant trade networks. AoB Plants 6:plu007.

Pautasso, M., Moslonka-Lefebvre, M., and Jeger, M. J. 2010. The number of links to and from the starting node as a predictor of epidemic size in smallsize directed networks. Ecol. Complex. 7:424-432.

Pleydell, D. R. J., Soubeyrand, S., Dallot, S., Labonne, G., Chadoeuf, J., Jacquot, E., and Thébaud, G. 2018. Estimation of the dispersal distances of an aphid-borne virus in a patchy landscape. PLoS Comput. Biol. 14: e1006085.

Probst, C., Nelson, M. E., Grove, G. G., Twomey, M. C., and Gent, D. H. 2016. Hop powdery mildew control through alteration of spring pruning practices. Plant Dis. 100:1599-1605.

Sanatkar, M. R., Scoglio, C., Natarajan, B., Isard, S. A., and Garrett, K. A. 2015. History, epidemic evolution, and model burn-in for a network of annual invasion: Soybean rust. Phytopathology 105:947-955.

Severns, P. M., Estep, L. K., Sackett, K. E., and Mundt, C. C. 2014. Degree of host susceptibility in the initial disease outbreak influences subsequent epidemic spread. J. Appl. Ecol. 51:1622-1630.

Severns, P. M., Sackett, K. E., Farber, D. H., and Mundt, C. C. 2018. Consequences of long-distance dispersal for epidemic spread: Patterns, scaling, and mitigation. Plant Dis. 103:177-191.

Severns, P. M., Sackett, K. E., and Mundt, C. C. 2015. Outbreak propagule pressure influences the landscape spread of a wind-dispersed, epidemiccausing, plant pathogen. Landsc. Ecol. 30:2111-2119.
Shaw, M. W., and Pautasso, M. 2014. Networks and plant disease management: Concepts and applications. Annu. Rev. Phytopathol. 52:477-493.

Simberloff, D. 2009. The role of propagule pressure in biological invasions. Annu. Rev. Ecol. Evol. Syst. 40:81-102.

Soubeyrand, S., Laine, A.-L., Hanski, I., and Penttinen, A. 2009. Spatiotemporal structure of host-pathogen interactions in a metapopulation. Am. Nat. 174:308-320.

Sutrave, S., Scoglio, C., Isard, S., Hutchinson, J. M. S., and Garrett, K. A. 2012. Identifying highly connected counties compensates for resource limitations when evaluating national spread of an invasive pathogen. PLoS One 7:e37793

Tack, A. J. M., and Laine, A.-L. 2014. Ecological and evolutionary implications of spatial heterogeneity during the off-season for a wild plant pathogen. New Phytol. 202:297-308.

Turechek, W. W., and Mahaffee, W. F. 2004. Spatial pattern analysis of hop powdery mildew in the Pacific Northwest: Implications for sampling. Phytopathology 94:1116-1128.

Turechek, W. W., Mahaffee, W. F., and Ocamb, C. M. 2001. Development of management strategies for hop powdery mildew in the Pacific Northwest. Plant Health Prog. 2:8.

Valdano, E., Fiorentin, M. R., Poletto, C., and Colizza, V. 2018. Epidemic threshold in continuous-time evolving networks. Phys. Rev. Lett. 120:068302.

With, K. A., Gardner, R. H., and Turner, M. G. 1997. Landscape connectivity and population distributions in heterogeneous environments. Oikos 78:151-169.

Wolfenbarger, S. N., Massie, S. T., Ocamb, C., Eck, E. B., Grove, G. G., Nelson, M. E., Probst, C., Twomey, M. C., and Gent, D. H. 2016. Distribution and characterization of Podosphaera macularis virulent on hop cultivars possessing R6-based resistance to powdery mildew. Plant Dis. 100: 1212-1221.

Wolfenbarger, S. N., Twomey, M. C., Gadoury, D. M., Knaus, B. J., Grünwald, N. J., and Gent, D. H. 2015. Identification and distribution of mating-type idiomorphs in populations of Podosphaera macularis and development of chasmothecia of the fungus. Plant Pathol. 64:1094-1102.

Wolfenbarger, S. N., Twomey, M. C., and Gent, D. H. 2017. Powdery mildew reaction of hop cultivars and USDA germplasm. Plant Dis. Manage. Rep. 11:V049.

Xu, X.-M., and Ridout, M. S. 1998. Effects of initial epidemic conditions, sporulation rate, and spore dispersal gradient on the spatio-temporal dynamics of plant disease epidemics. Phytopathology 88:1000-1012. 